\title{
Analgesic Effect of Noninvasive Brain Stimulation for Neuropathic Pain Patients: A Systematic Review
}

Kun-Long Zhang $\cdot$ Hua Yuan · Fei-Fei Wu $\cdot$ Xue-Yin Pu

Bo-Zhi Liu $\cdot$ Ze Li $\cdot$ Kai-Feng Li $\cdot$ Hui Liu $\cdot$ Yi Yang $\cdot$ Ya-Yun Wang (D

Received: December 24, 2020 / Accepted: February 26, 2021 / Published online: March 22, 2021

(C) The Author(s) 2021

\begin{abstract}
Introduction: The objective of this review is to systematically summarize the consensus on best practices for different NP conditions of the two most commonly utilized noninvasive brain stimulation (NIBS) technologies, repetitive transcranial magnetic stimulation (rTMS), and transcranial direct current stimulation (tDCS).

Methods: PubMed was searched according to the predetermined keywords and criteria. Only English language studies and studies published up to January 31, 2020 were taken into consideration. Meta-analyses, reviews, and systematic
\end{abstract}

K.-L. Zhang · F.-F. Wu - X.-Y. Pu - B.-Z. Liu - Z. Li · K.-F. Li · H. Liu · Y. Yang · Y.-Y. Wang ( $₫)$ Specific Lab for Mitochondrial Plasticity Underlying Nervous System Diseases, National Demonstration Center for Experimental Preclinical Medicine Education, Air Force Medical University, Xi'an 710032, China

e-mail: wangyy@fmmu.edu.cn

\section{K.-L. Zhang · H. Yuan}

Department of Rehabilitation Medicine, Xi-Jing

Hospital, Air Force Medical University, Xi'an

710032, China

H. Liu · Y. Yang

Department of Human Anatomy, Yan-An

University, Yan'an 716000, China

\section{Y.-Y. Wang}

State Key Laboratory of Military Stomatology,

School of Stomatology, The Fourth Military Medical

University, Xi'an, China reviews were excluded first, and those related to animal studies or involving healthy volunteers were also excluded. Finally, 29 studies covering 826 NP patients were reviewed.

Results: The results from the 24 enrolled studies and $736 \mathrm{NP}$ patients indicate that rTMS successfully relieved the pain symptoms of 715 (97.1\%) NP patients. Also, five studies involving 95 NP patients $(81.4 \%)$ also showed that tDCS successfully relieved NP. In the included studied, the M1 region plays a key role in the analgesic treatment of NIBS. The motor evoked potentials (MEPs), the 10-20 electroencephalography system (EEG 10/20 system), and neuro-navigation methods are used in clinical practice to locate therapeutic targets. Based on the results of the review, the stimulation parameters of rTMS that best induce an analgesic effect are a stimulation frequency of $10-20 \mathrm{~Hz}$, a stimulation intensity of $80-120 \%$ of RMT, 1000-2000 pulses, and 5-10 sessions, and the most effective parameters of tDCS are a current intensity of $2 \mathrm{~mA}$, a session duration of 20-30 min, and 5-10 sessions.

Conclusions: Our systematically reviewed the evidence for positive and negative responses to rTMS and tDCS for NP patient care and underscores the analgesic efficacy of NIBS in patients with NP. The treatment of NP should allow the design of optimal treatments for individual patients. 
Keywords: Neuropathic pain; Noninvasive brain stimulation; Repetitive transcranial magnetic stimulation; Review; Transcranial direct current stimulation

\section{Key Summary Points}

Neuropathic pain (NP) in this review is categorized as typical NP (TNP) resulting from diabetes, stroke, spinal cord injury (SCI) and nerve lesions, and special NP (SNP), including facial NP (FaNP), cancer NP (CaNP), phantom limb NP (PhanNP), and other malformations.

Commonly used parameters of rTMS were a stimulation frequency of $10-20 \mathrm{~Hz}$, a stimulation intensity of $80-120 \%$ of the resting motor threshold, 1000-2000 pulses, and 5-10 sessions.

The most common parameters of tDCS were a current intensity of $2 \mathrm{~mA}$, a session duration of 20-30 min, and 5-10 sessions.

\section{DIGITAL FEATURES}

This article is published with digital features, including a summary slide, to facilitate understanding of the article. To view digital features for this article go to https://doi.org/10.6084/ m9.figshare.14105999.

\section{INTRODUCTION}

Neuropathic pain (NP) has been defined by the International Association for the Study of Pain as pain caused by a lesion or disease of the somatosensory system [1-3]. A treatment that addresses the dynamic neural system changes in $\mathrm{NP}$ is needed. Noninvasive brain stimulation (NIBS) is one such promising therapeutic technique [4].

NIBS is based on the interaction of electricity or magnetism with the body [5-8] (Fig. 1). Present NIBS techniques include the two most commonly utilized technologies, repetitive transcranial magnetic stimulation (rTMS) and transcranial direct current stimulation (tDCS) [9]. NIBS guidelines for the clinic are key for making patient care decisions in rehabilitation procedures, but no consensus of best practices for different NP conditions currently exists [10-16]. Therefore, we systematically reviewed the evidence for positive and negative responses to rTMS and tDCS for NP patient care.

\section{METHODS}

\section{Literature Search Strategy}

Studies published up to January 31, 2020 were taken into consideration for obtaining relevant literature findings. A PubMed search for articles published in and after 2010 with keywords "rTMS/tDCS AND neuropathic pain" identified 237 studies from different countries. The reference lists of articles that met the eligibility criteria were further screened to identify additional studies that may fall within the scope of this review.

\section{Inclusion and Exclusion Criteria and Screening Process}

Based on the abstracts of the studies, we first made an initial judgement on the 237 studies that might be of value, including only English language studies and excluding meta-analyses, reviews, and systematic reviews. For the remaining 162 studies, after reviewing the full text and excluding animal studies and studies of healthy volunteers, we made a final decision on which studies should be included in the review. In other words, studies eligible to be included in this review had to meet the following inclusion criteria: (1) only English language studies were included; (2) meta-analyses, reviews, and systematic reviews were excluded; (3) animal studies were excluded; (4) studies involving healthy volunteers were excluded.

Finally, 29 studies covering $826 \mathrm{NP}$ patients were reviewed here. The summary on search strategy can be seen in Fig. 2. Through reading 


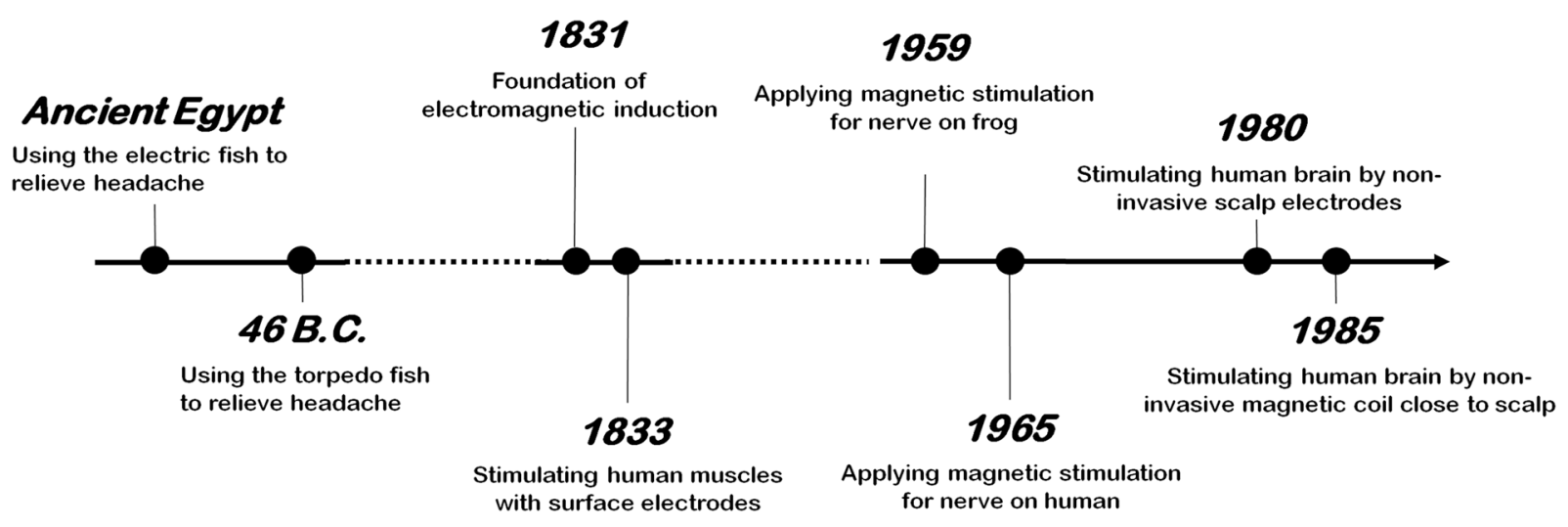

Fig. 1 Origin and development of NIBS. NIBS is based on the interaction of electricity or magnetism with the body. The historically important events related to brain electric or magnetic stimulation were indicated

the full text, we grasped the situation of NP patients in the 29 studies. In addition to counting the number of patients, we also made a statistical summary according to the treatment situation of NIBS, the targeted sites, and the different treatment parameters. This article is based on previously conducted studies and does not contain any new studies with human participants or animals performed by any of the authors. Written informed consent was obtained for the use of the two patients' photographs in this publication.

\section{Data Synthesis}

This study used aggregate data where possible, in accordance with the Preferred Reporting Items for Systematic Reviews and Meta-Analysis (PRISMA) guidelines [17].

\section{Categories of NP in the Present Review}

NP is classified as central or peripheral based on the anatomical location of the injury or disease [18]. Central NP is due to a lesion or disease of the spinal cord and/or brain, the most common causes of which include stroke and spinal cord injury. In the present review, nine types of NP have been studied. Among them, two types of NP belong to the central NP, including stroke and spinal cord injury, while seven types of NP belong to the peripheral NP, including diabetic neuropathy, nerve injury, facial pain, phantom limb pain, cancerous pain, malformation, and bladder pain syndrome. It should be noticed, however, that the most common cases of NP are the following four types including (1) stroke, (2) spinal cord injury, (3) nerve injury, and (4) diabetic neuropathy, which have been named as typical NP (TNP) in the manuscript. While the remaining types of NP have been named as special NP (SNP), including (1) facial pain, (2) phantom limb pain, (3) cancerous pain, and (4) others (malformation and bladder pain syndrome), because of the low incidences of such NP. The present classification could help the clinician deeply understand the analgesic effect of noninvasive brain stimulation for both typical and special NP.

In addition, according to the positive or negative effect of NIBS on NP in all reports, all NP patients can be divided into four categories: (1) rTMS-P, all NP patients with a positive analgesic effect from rTMS treatment; (2) rTMS$\mathrm{N}$, all NP patients with a negative analgesic effect from rTMS treatment; (3) tDCS-P, all NP patients with a positive analgesic effect from tDCS treatment; (4) tDCS-N, all NP patients with a negative analgesic effect from tDCS treatment.

The patients with NP have different symptoms such as paroxysmal pain, hyperalgesia, and allodynia. An increased sensation of pain in response to a normally painful stimulus is termed hyperalgesia, which can be assessed using painful thermal (cold or heat) or punctate (e.g., pinprick) stimuli whether patients have 


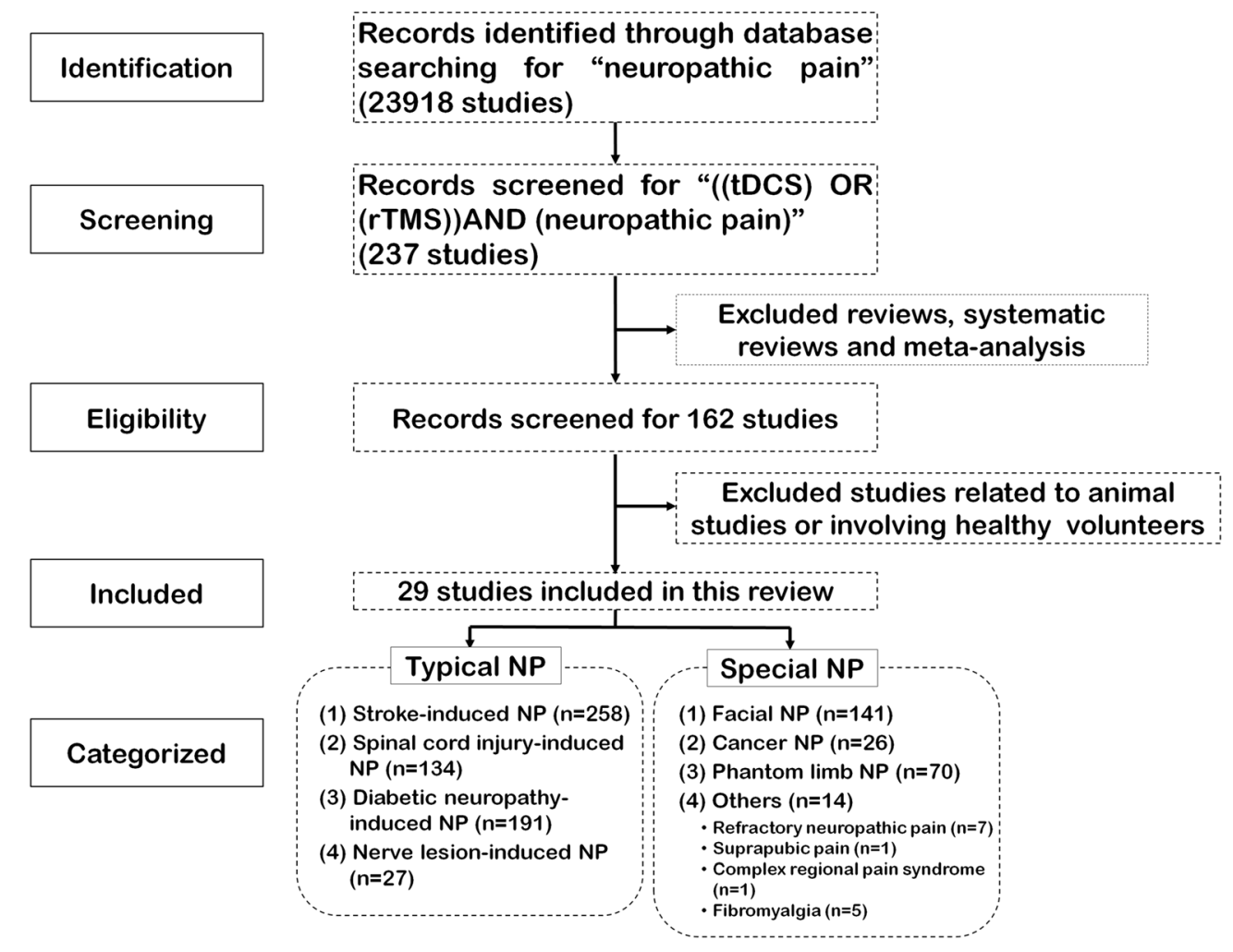

Fig. 2 PRISMA (Preferred Reporting Items for Systematic Reviews and Meta-Analysis) flow diagram. A PubMed search for articles published in and after 2010 with keywords "rTMS/tDCS AND neuropathic pain" identified 237 studies from different countries. Meta-analyses, reviews, and systematic reviews were excluded. Among the 162 filtered studies, those related to animal studies or involving healthy volunteers were excluded. Finally, 29

improved hyperalgesia or allodynia after NIBS treatment [1]. The analgesic effects of rTMS or tDCS on NP patients are based on a total of eight kinds of NP screening tools including the Visual Analog Scale (VAS) [14, 19-32], Numeric Rating Scale (NRS) [33-41], Neuropathic Pain Questionnaire (NPQ) [30], Visual Numerical Scale (VNS) [42], Quantitative Sensory Testing (QST) [31], Verbal Descriptor Scale (VDS) [32] and McGill Pain Questionnaire/Short-Form McGill Pain Questionnaire (MPQ/SF-MPQ) $[23,30]$. Pain relief is generally defined as an improvement of more than $20 \%$ in the pain score [1]. studies covering $826 \mathrm{NP}$ patients were reviewed here. Instead of using the classic central and peripheral classifications, we classified the most common (large number of cases) types of NP as typical NP (TNP), including diabetic neuropathy, stroke, spinal cord injury (SCI), and nerve injury. The remaining clinically rare types are classified as special NP (SNP), such as facial pain, phantom limb pain, cancer pain, and other types of pain

\section{RESULTS}

\section{Analgesic Effect of NIBS on TNP and SNP}

As shown in Table 1, the results from the 24 enrolled studies and 736 NP patients indicate that rTMS successfully relieved the pain symptoms of $715(97.1 \%)$ NP patients. Only 21 NP patients (2.9\%) did not experience pain relief, as reported by De Oliveira RA et al. [30]. Among 715 NP patients who experienced a significant analgesic effect of rTMS, $68.8 \%(n=492)$ had TNP, while $31.2 \%(n=223)$ had SNP.

As also outlined in Table 1 , a total of six articles and $125 \mathrm{NP}$ patients were involved in tDCS treatment. Among them, five studies 
Table 1 Summary of the 29 manuscripts of analgesic effects by NIBS (both rTMS and tDCS) on NP patients

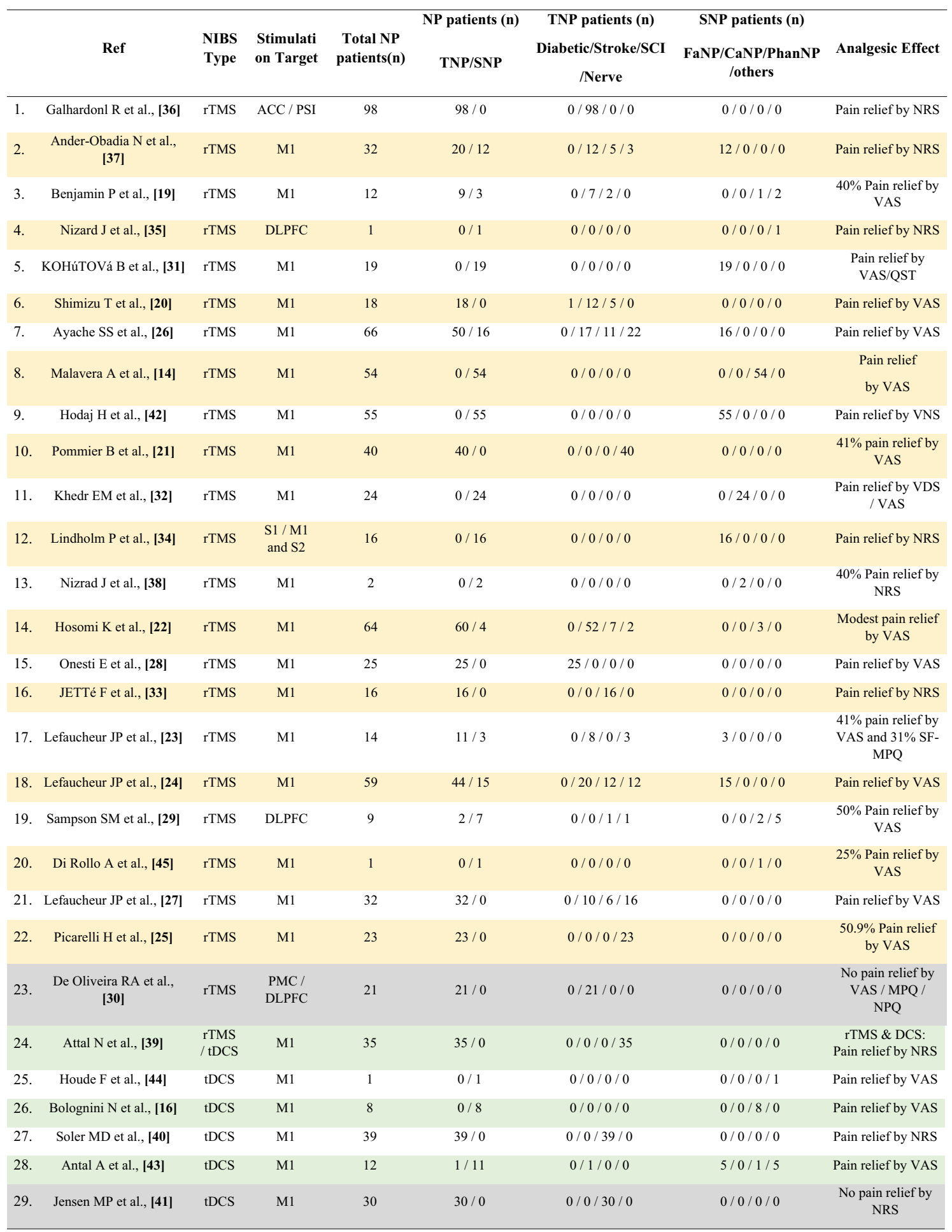

Studies of rTMS treatment are labeled yellow, studies of tDCS treatment are labeled green, and studies of ineffective treatment are labeled gray

$r T M S$ repetitive transcranial magnetic stimulation, $t D C S$ transcranial direct current stimulation, $A C C$ anterior cingulate cortex, $P S I$ posterior superior insula, $M I$ primary motor cortex, $D L P F C$ dorsolateral prefrontal cortex, $P M C$ premotor cortex, $S 1$ primary somatosensory cortex, $S 2$ secondary somatosensory cortex 
involving $95 \mathrm{NP}$ patients (76.0\%) also showed that tDCS successfully relieved NP $[39,40,43,44]$. Thirty NP patients $(24.0 \%)$ did not experience pain relief, as reported by Jensen MP et al. [41]. Among $95 \mathrm{NP}$ patients who experienced a significant analgesic effect of tDCS, 81 had TNP (85.3\%) and 14 had SNP (14.7\%).

\section{TNP}

As shown in Fig. 3, among 575 patients with TNP, 505 received rTMS treatment for TNP induced by stroke $(50.9 \%, n=257)$, nerve trunk or root legions $(30.9 \%, n=156)$, SCI $(12.9 \%$, $n=65)$, and diabetic neuropathy $(5.3 \%, n=27)$. Furthermore, among the 575 patients with TNP, 105 patients received tDCS treatment, including
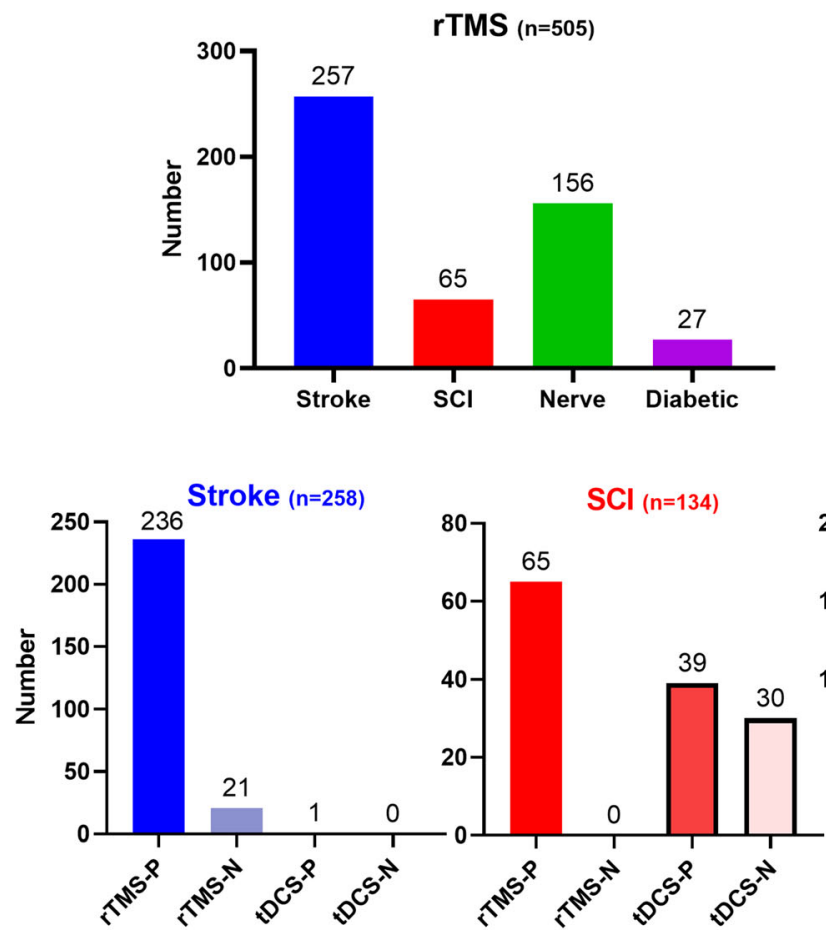

Fig. 3 Effect of NIBS on different subtypes of TNP. The figure shows the therapeutic effect of NIBS on four subtypes of typical NP (TNP) (above): (1) stroke (blue), (2) spinal cord injury (SCI) (red), (3) nerve trunk or root lesions (green), and (4) diabetes (purple). In the same subtype of data (below), the dark color represents the positive treatment results and the light color represents the
TNP induced by SCI $(65.7 \%, n=69)$, lesions of the nerve trunks or roots $(33.3 \%, n=35)$, and stroke $(1.0 \%, n=1)$. There were no patients with TNP induced by diabetic neuropathy $(n=0)$.

\section{Stroke-Induced TNP}

Stroke-induced NP occurs in $2-8 \%$ of stroke survivors, with a prevalence of up to $18 \%$ in patients with somatosensory deficits and about half of the lesions affect solely the spinothalamic pathway, which may severely impair their quality of life $[19,36,46]$. Among NIBS-treated patients with stroke-induced TNP $(n=258)$ (Fig. 3), most were rTMS-P $(91.5 \%, n=236)$, and only one patient was tDCS-P $(3.9 \%, n=1)$. Unfortunately, 21 patients were rTMS-N (8.1\%). However, no reports described cases of tDCS-N
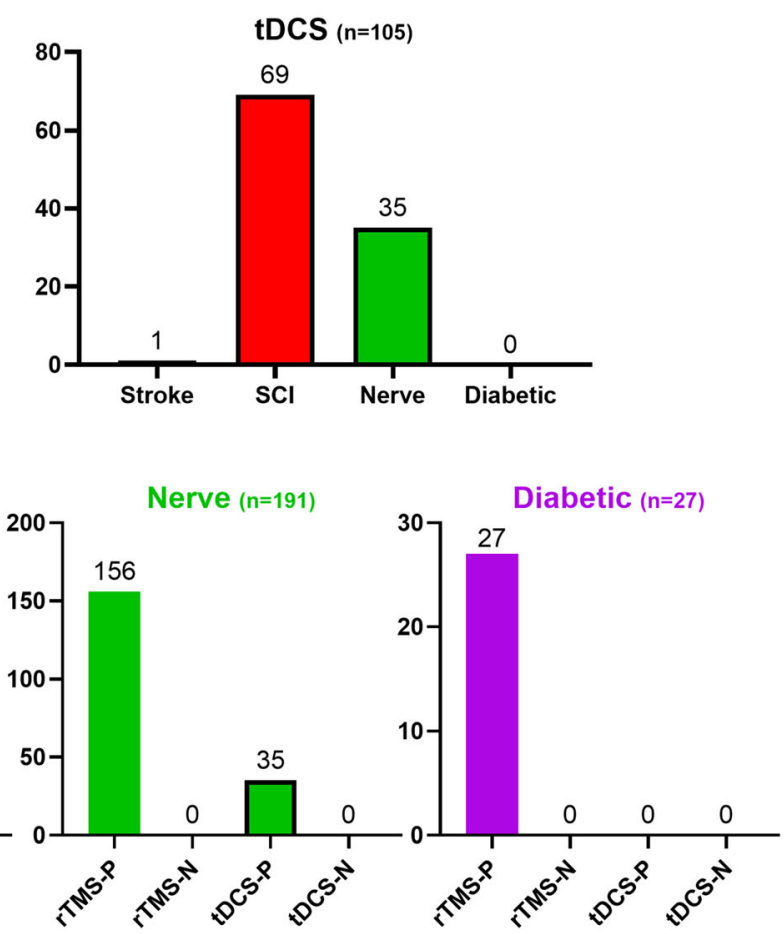

negative treatment results. All NP patients can be divided into four categories: (1) rTMS-P, all NP patients with a positive analgesic effect from rTMS treatment; (2) rTMS$\mathrm{N}$, all NP patients with a negative analgesic effect from rTMS treatment; (3) tDCS-P, all NP patients with a positive analgesic effect from tDCS treatment; and (4) tDCS-N, all NP patients with a negative analgesic effect from tDCS treatment 
$(n=0)$. This result may imply that rTMS is effective in refractory and drug-resistant poststroke NP, although this conclusion deserves confirmation in larger replication studies.

\section{SCI-Induced TNP}

SCI-induced NP ranks among the most debilitating complications of traumatic SCI, affecting $>80 \%$ of patients within 5 years after trauma and leading to NP in up to $59 \%$ of individuals [36]. Among the NIBS-treated patients with TNP induced by SCI $(n=134)$ (Fig. 3), half were rTMS-P $(48.5 \%, n=65)$, and nearly one-third were tDCS-P $(29.1 \%, n=39)$. Unfortunately, 30 were tDCS-N (22.4\%). No reports described cases of rTMS-N $(n=0)$. This result may imply that rTMS is a reliable treatment for SCI-induced NP. However, the application of tDCS treatment for SCI-induced TNP patients may need much more careful assessment.

\section{Diabetic Neuropathy-Induced TNP}

Diabetic NP is the most common peripheral neuropathy globally, and its principal pathology involves distal autonomic and sensory dysfunction, predominantly affecting the patient's feet, estimated to affect approximately $30 \%$ of people with diabetes [47]. Among NIBStreated diabetic TNP patients $(n=27)$ (Fig. 3), all of them were rTMS-P (100\%). There were no cases of rTMS-N $(n=0)$, tDCS-P $(n=0)$, or tDCS$\mathrm{N}(n=0)$. This result, however, does not indicate that rTMS is most suitable for this type of NP because of the limited number of clinical trials. We can only advocate caution when we encounter this kind of complicated pain condition.

\section{Nerve Lesion-Induced TNP}

Lesions of the nerve can affect peripheral nerves, plexus trunks, or spinal nerve roots, causing paralysis, paresthesia, and pain [21, 48]. Among NIBS-treated patients with TNP induced by lesions of the nerve trunks or roots $(n=191)$ (Fig. 3), most of them were rTMS-P (81.7\%, $n=156)$, and some were tDCS-P $(18.3 \%$, $n=35)$. There were no cases of either rTMS-N $(n=0)$ or tDCS-N $(n=0)$. This result could imply that NIBS is effective for damaged nerveinduced NP, which would be of benefit to NIBS supporters and victims of drug-resistant NP.

\section{SNP}

As shown in Fig. 4, among 251 patients with SNP, $92.0 \%(n=231)$ received rTMS treatment, and only $8.0 \%(n=20)$ received tDCS treatment. Among the 231 rTMS-treated SNP patients (Fig. 4), 58.9\% $(n=136)$ had FaNP, $11.3 \%(n=26)$ had CaNP, $26.4 \%(n=61)$ had PhanNP, and others $(3.4 \%, n=8)$. Among the 20 tDCS-treated SNP patients, $25.0 \%(n=5)$ had FaNP, $45.0 \% \quad(n=9)$ had PhanNP, others $(30.0 \%, n=6)$ and none $(n=0)$ had CaNP.

\section{FaNP}

NIBS has not been frequently studied in patients with FaNP until now. As shown in Fig. 4 , in total, among the 141 FaNP patients, most were rTMS-P $(96.5 \%, n=136)$, and some were tDCS-P $(3.5 \%, n=5)$. There were no cases of either rTMS-N $(n=0)$ or tDCS-N $(n=0)$. Previous literature data concerning 86 patients with FaNP [31, 37, 42] indicate that motor cortex rTMS provides transient and modest subjective pain relief. Hodaj et al. [42] have reported that that in 55 patients (cluster headache, $n=19$; trigeminal $\mathrm{NP}, n=21$; atypical facial pain, $n=15$ ), three pain measures (intensities of permanent pain and paroxysmal pain and daily number of painful attacks) were significantly decreased. Therefore, this result could imply that NIBS is suitable for FaNP patients in the clinic.

\section{CaNP}

CaNP may arise from nerve compression or direct infiltration by a growing tumor or secondarily from changes in the neuronal media resulting from cancer and is difficult to control [32]. As shown in Fig. 4, among the 26 CaNP patients, all were rTMS-P (100\%). There were no cases of rTMS-N $(n=0)$, tDCS-P $(n=0)$, or tDCS$\mathrm{N}(n=0)$. Therefore, the present results indicate the potential efficacy of rTMS for CaNP patients. 

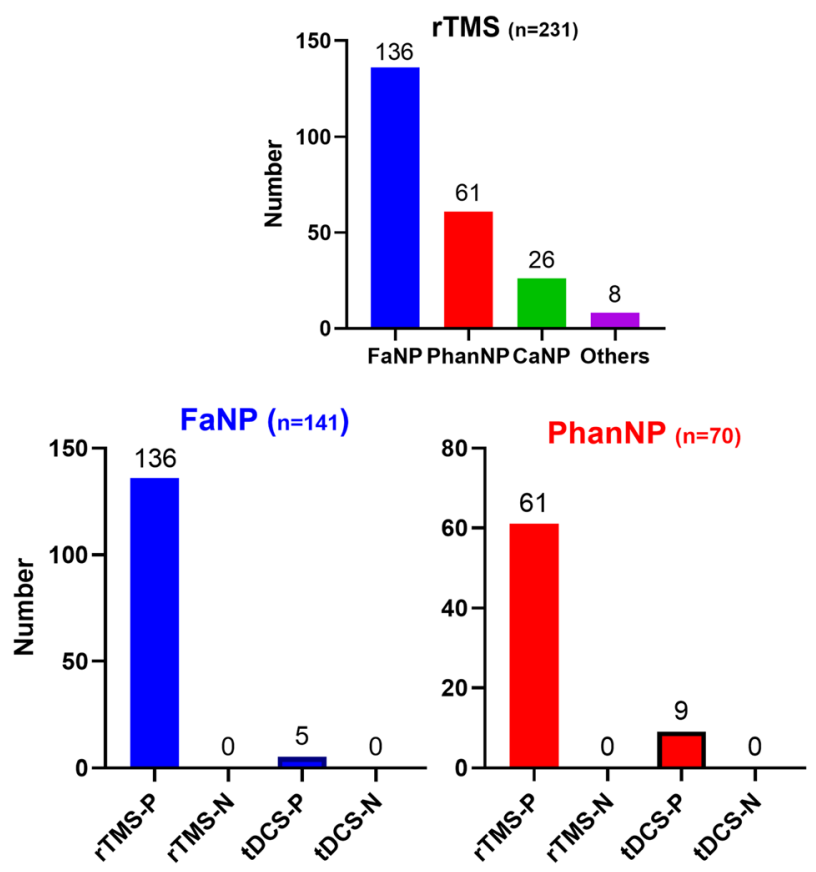

Fig. 4 Effect of NIBS on different subtypes of SNP. The figure shows the therapeutic effect of NIBS on four subtypes of special NP (SNP) (above): (1)facial NP (FaNP) (blue), (2) phantom limb NP (PhanNP) (red), (3) cancer NP (CaNP) (green), and (4) other conditions (purple), such as malformation, and bladder pain syndrome. In the same subtype of data (below), the dark color represents the positive treatment results and the light color

\section{PhanNP}

PhanNP is very common after limb amputation and difficult to treat, usually responding poorly to conventional pain treatments [45]. As shown in Fig. 4, among the 70 PhanNP patients, most were rTMS-P $(87.1 \%, n=61)$, and $12 . \%$ were tDCS-P $(n=9)$. There were no cases of rTMS-N $(n=0)$ or tDCS-N $(n=0)$. Nevertheless, the positive analgesic effects of NIBS deserve further research in a large number of populations experiencing NP in an amputated limb.

\section{Other SNPs}

Other conditions, such as complex regional pain syndrome (CRPS) [44], fibromyalgia, or polyneuropathy [41], can also cause NP. Among NIBS-treated patients with TNP induced by other sources $(n=14)$ (Fig. 4), most of them were rTMS-P $(57.1 \%, n=8)$, and some were
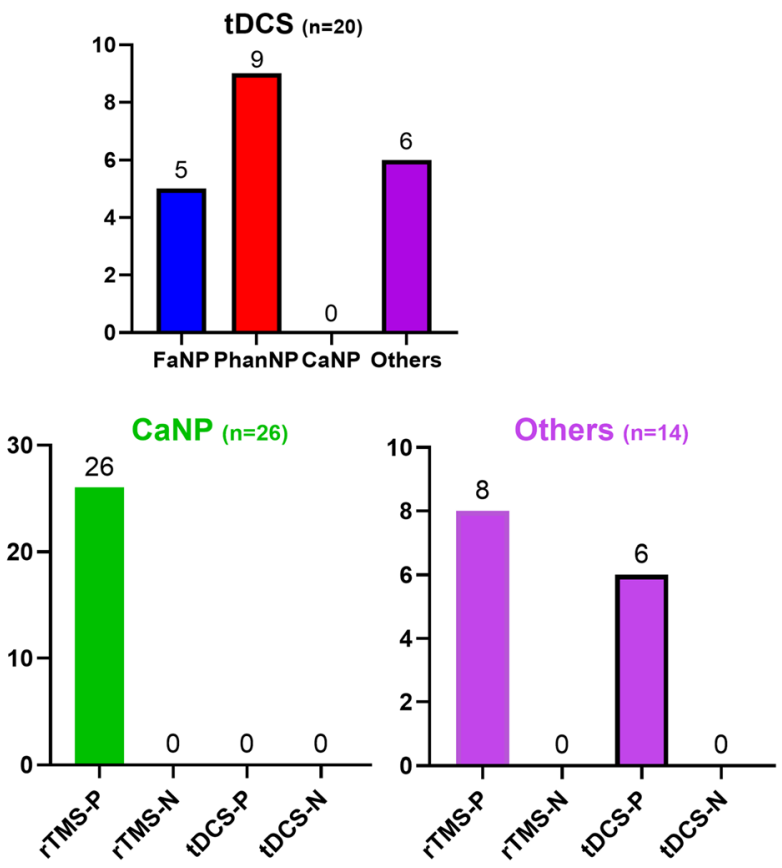

represents the negative treatment results. All NP patients can be divided into four categories: (1) rTMS-P, all NP patients with a positive analgesic effect from rTMS treatment; (2) rTMS-N, all NP patients with a negative analgesic effect from rTMS treatment; (3) tDCS-P, all NP patients with a positive analgesic effect from tDCS treatment; and (4) tDCS-N, all NP patients with a negative analgesic effect from tDCS treatment

tDCS-P $(42.9 \%, n=6)$. There are no cases of either rTMS-N $(n=0)$ or tDCS-N $(n=0)$. This result could reflect the fact that rTMS could not relieve pain effectively in some clinical trials, and tDCS could be attempted and potentially effective.

\section{Analgesic Target and Localization of rTMS}

As shown in Table 1 and Fig. 3, among the 484 TNP patients with rTMS-P, $79.4 \%(n=384)$ of the rTMS treatments targeted M1, 10.1\% $(n=49)$ targeted the anterior cingulate cortex (ACC), $10.1 \%(n=49)$ targeted the posterior superior insula (PSI), and $0.4 \%(n=2)$ targeted the dorsolateral prefrontal cortex (DLPFC).

As shown in Table 1 and Fig. 4, among the 231 SNP patients with rTMS-P, almost all $(96.5 \%, n=223)$ were administered rTMS that 
targeted M1, and only 3.5\% $(n=8)$ received rTMS that targeted the DLPFC. There are no reports on SNP patients with a positive response to rTMS targeting other brain regions. This may suggest that for NP patients with FaNP, CaNP, or PhanNP, M1-targeted rTMS should be the first choice.

As mentioned above, $79.4 \%$ of effective analgesia targeted M1 (Table 1), which means that the M1 region plays a key role in the analgesic treatment of NIBS. Therefore, it is crucial to accurately localize the M1 region during treatment. Currently, motor evoked potentials (MEPs), the 10-20 electroencephalography system (EEG 10/20 system) and neuro-navigation methods are used in clinical practice to locate M1 targets.

\section{MEP-Based Method}

Nineteen of 30 selected studies used the MEPbased method to target M1. The optimal stimulation site, the motor hot spot, could be determined according to visual detection of muscle twitches with this method [22] (Fig. 5a). The resting motor threshold (RMT) is defined as the minimum stimulator intensity needed to evoke at least one visible muscle twitch in the extensor hallucis brevis muscle while maintaining a relaxed position $[20,22,24,25,32,33,37,42]$. The DLPFC/PMC location can also be defined with respect to M1 (5 cm anterior to M1) [29, 30, 49, 50] (Fig. 5a). MEP recordings are simple and maneuverable and are by far the most widely used method to locate M1 in clinical rTMS treatment.

\section{EEG 10/20 System Method}

The EEG $10 / 20$ system is the standard electrode placement system developed by the International Brain Mapping Society [51]. It is characterized by the arrangement of electrodes with respect to the size and shape of the skull. Electrodes are appropriately distributed in the main part of the skull in the standard position (Fig. 5b). Marker points with the same name can be considered to correspond to roughly the same anatomical regions of the brains of different subjects. In the literature, the stimulating electrode is typically placed over C3 or C4 (in the EEG $10 / 20$ system) to target M1 contralateral to the painful side $[16,39-41,52]$. This method is simple and convenient and is also widely used in clinical practice.

\section{Neuro-Navigation Method}

A $1 \times 1 \times 1 \mathrm{~mm}^{3}$ 3D T1-weighted MRI for frameless stereotaxic neuro-navigation can be used to define the target of magnetic stimulation, for example, the subdivision of M1 representing the hand [53, 54] (Fig. 5c). Of the articles we reviewed, six studies reported the use of a neuro-navigation technique that can detect hypermetabolic or hyperactive cortical regions by positron emission tomography (PET) or functional magnetic resonance imaging (fMRI) $[19,21,23,26,34,36]$. This method should allow better reproducibility and accuracy regarding the identification of the stimulation site and potentially increased efficacy [12].

\section{Stimulation Parameters of Analgesic rTMS}

rTMS paradigms are mainly defined with four stimulation parameters: stimulation frequency, stimulation intensity, number of pulses, and number of sessions (Table 2).

\section{Stimulation Frequency}

Stimulation frequency is the most crucial parameter for rTMS therapeutic applications [12]. rTMS typically falls into two categories: high-frequency rTMS (HF rTMS), with a frequency between 5 and $20 \mathrm{~Hz}$, and low-frequency rTMS (LF rTMS), with a frequency at $1 \mathrm{~Hz}$ or less. HF rTMS is commonly considered excitatory, whereas LF rTMS is considered inhibitory [55-58]. Among the 24 rTMS studies, HF rTMS was used in $21(87.5 \%)$, and LF rTMS was used in three (12.5\%). Among the $21 \mathrm{HF}$ rTMS studies, 5-10 Hz stimulation was used in 17 studies $(81.0 \%)$, and $20 \mathrm{~Hz}$ stimulation was used in four studies (19.0\%).

\section{Stimulation Intensity}

To indicate treatment dosage, the RMT is determined at the initial treatment session, and treatment intensity is titrated from 80 to $120 \%$ of the RMT depending upon patient tolerance 
[59]. Among the 24 rTMS studies, 11 selected $90 \%$ of the RMT, eight selected $80 \%$ of the RMT, and five selected at least $100 \%$ of the RMT as the final intensity.

\section{Pulse Number}

According to the different number of pulses, TMS is usually divided into single-pulse TMS (sTMS), paired-pulse TMS (pTMS), and rTMS [60-62]. rTMS is mostly used for analgesia [12]. Of the 24 rTMS studies in this review, 18 studies (75\%) used between 1000 and 2000 pulses. Three studies (12.5\%) used 500-600 pulses, and three studies (12.5\%) used 2500-3000 pulses.

\section{Session Number}

Although the duration of the effects of a single rTMS is short-lasting, longer-lasting subsequent effects can be achieved by using longer periods of stimulation or multiple rTMS sessions [63]. Researchers tend to use more than a single rTMS session, since the most robust analgesic effects were found to occur 2-4 days after an rTMS session, and the analgesic effect remained for a fortnight after the last treatment, but this beneficial effect generally lasted less than 1 month $[12,26]$.

C

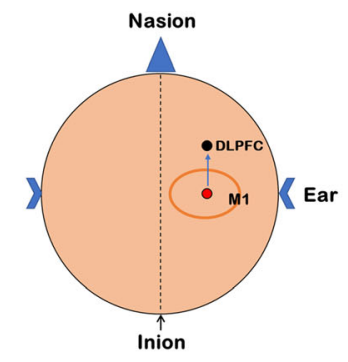

B

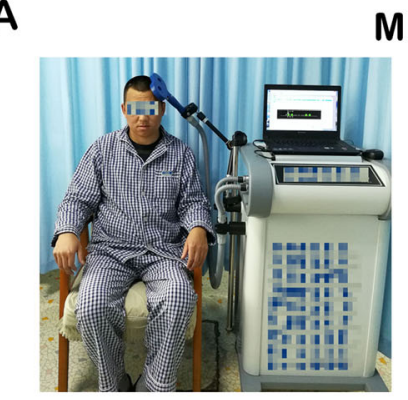

MEP
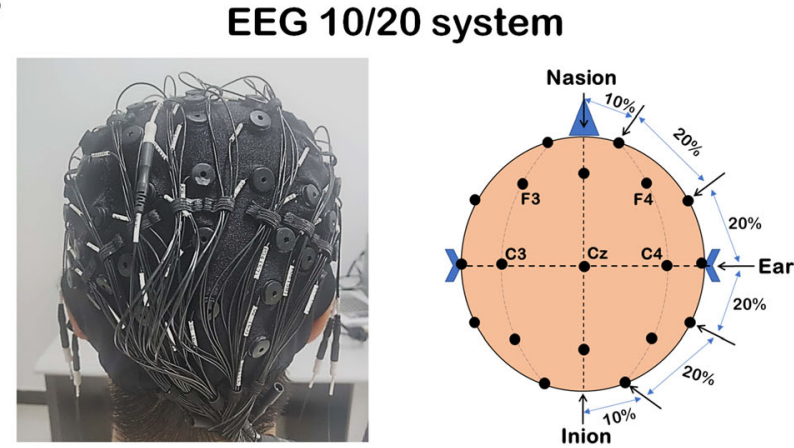

Fig. 5 Common methods for targeting brain regions in NIBS. a MEP-based method was used to target M1 of the patient (left). In detail, the coil is placed over the contralateral hemisphere in the area corresponding to the M1, and the optimal stimulation site is found by moving the coil over the scalp to the site that evokes the largest MEP amplitude in the resting state of target muscle (the orange circle represents the M1 area of the brain, and the red spot represents the optimal stimulation site), and then along the central axis direction forward $5 \mathrm{~cm}$ is considered DLPFC region (the black spot) (right). b Picture of electrode cap on patient's head, in which the electrodes are properly distributed in the main part of the skull in a standard position (left). Schematic diagram of standard electrode placement for EEG 10/20 system (right). The position of the $\mathrm{C} 3 / \mathrm{C} 4$ electrode is assumed to correspond to the $\mathrm{M} 1$ region, while the DLPFC region is targeted by placing the stimulating electrode on the scalp at F3/F4. $\mathrm{Cz}=$ vertex. $\mathbf{c}$ Schematic diagram of using neuro-navigation to target brain regions. The patient lies on the bed in a relaxed posture, and neuro-navigation is used to define the target of magnetic stimulation which is the M1 in its subdivision representing the hand 
Table 2 Summary of the parameters of rTMS on NP patients

\begin{tabular}{|c|c|c|c|c|c|}
\hline & \multirow[b]{2}{*}{ Ref } & \multicolumn{4}{|c|}{ rTMS Parameters } \\
\hline & & $\begin{array}{c}\text { Stimulation } \\
\text { Frequency }(\mathrm{Hz})\end{array}$ & $\begin{array}{c}\text { Stimulation } \\
\text { Intensity (\% RMT) }\end{array}$ & $\begin{array}{c}\text { Pulse } \\
\text { Number (n) }\end{array}$ & $\begin{array}{c}\text { Session } \\
\text { Number (n) }\end{array}$ \\
\hline 1. & Galhardonl R et al., 2019 [36] & 10 & 90 & 1500 & 5 \\
\hline 2. & Ander-Obadia $\mathrm{N}$ et al., 2018 [37] & 10 & 90 & 2000 & 2 \\
\hline 3. & Benjamin P et al., 2018 [19] & 20 & 80 & 1600 & 4 \\
\hline 4. & Nizard J et al., 2018 [35] & 1 & 110 & 1200 & 6 \\
\hline 5. & KOHúTOVá B et al., 2017 [31] & 5 & 80 & 600 & 1 \\
\hline 6. & Shimizu T et al., 2017 [20] & 5 & 90 & 500 & 5 \\
\hline 7. & Ayache SS et al., 2016 [26] & 10 & 90 & 3000 & 3 \\
\hline 8. & Malavera A et al., 2016 [14] & 10 & 90 & 1200 & 10 \\
\hline 9. & Hodaj H et al., 2015 [42] & 10 & 80 & 2000 & 7 \\
\hline 10. & Pommier B et al., 2015 [21] & 20 & 80 & 1600 & 4 \\
\hline 11. & Khedr EM et al., 2015 [32] & 20 & 80 & 2000 & 10 \\
\hline 12. & Lindholm P et al., 2015 [34] & 10 & 90 & 1000 & 5 \\
\hline 13. & Nizrad J et al., 2015 [38] & 10 & 80 & 2000 & 5 \\
\hline 14. & Hosomi K et al., 2013 [22] & 5 & 90 & 1500 & 10 \\
\hline 15. & Onesti E et al., 2013 [28] & 20 & 100 & 1500 & 5 \\
\hline 16. & JETTé F et al., 2013 [33] & 10 & 90 & 2000 & 1 \\
\hline 17. & Lefaucheur JP et al., 2012 [23] & 10 & 90 & 2000 & 3 \\
\hline 18. & Lefaucheur JP et al., 2011 [24] & 10 & 90 & 2000 & 2 \\
\hline 19. & Sampson SM et al., 2011 [29] & 1 & 110 & 1600 & 15 \\
\hline 20. & Di Rollo A et al., 2011 [45] & 1 & 80 & 600 & 10 \\
\hline 21. & Lefaucheur JP et al., 2010 [27] & 10 & 90 & 2000 & 2 \\
\hline 22. & Picarelli H et al., 2010 [25] & 10 & 100 & 2500 & 10 \\
\hline 23. & De Oliveira RA et al., 2014 [30] & 10 & 120 & 1250 & 10 \\
\hline 24. & Attal $\mathrm{N}$ et al., 2016 [39] & 10 & 80 & 3000 & 3 \\
\hline
\end{tabular}

Study of ineffective treatment is labeled gray

$r T M S$ repetitive transcranial magnetic stimulation, $R M T$ resting motor threshold

\section{Stimulation Parameters of Analgesic tDCS}

The design of a tDCS protocol particularly requires establishing three parameters: current intensity, session duration, and number of sessions (Table 3).

\section{Current Intensity}

The stimulation form of tDCS includes anode tDCS (atDCS) and cathode tDCS (ctDCS). When a positively charged electrode (anode) is placed on the surface of the skull, a portion of the current is thought to enter the brain and polarize the neurons close to the electrode, thereby increasing neuronal firing. Conversely, a negatively charged electrode (cathode) decreases the excitability of the cortex and induces hyperpolarization of the neurons $[64,65]$. The tDCS used in the studies summarized in the present review achieved an analgesic effect when the current intensity was 1 or $2 \mathrm{~mA}$ (Table 3).

\section{Session Duration}

Session duration is the total amount of time the patient spends in treatment $[39,66]$. The tDCS used in the present review could achieve 
Table 3 Summary of the parameters of tDCS on NP patients

\begin{tabular}{lcccc}
\hline & & \multicolumn{3}{c}{ tDCS Parameters } \\
\cline { 3 - 5 } & & $\begin{array}{c}\text { Current } \\
\text { Intensity (mA) }\end{array}$ & $\begin{array}{c}\text { Session } \\
\text { Duration (min) }\end{array}$ & $\begin{array}{c}\text { Session } \\
\text { Number (n) }\end{array}$ \\
\hline 1. & Attal N et al., 2016 [39] & 2 & 30 & 3 \\
\hline 2. & Houde F et al., 2020 [44] & 2 & 25 & 5 \\
\hline 3. Bolognini N et al., 2013 [16] & 2 & 15 & 5 \\
\hline 4. & Soler MD et al., 2010 [40] & 2 & 20 & 10 \\
\hline 5. $\quad$ Antal A et al., 2010 [43] & 1 & 20 & 5 \\
\hline 6. Jensen MP et al., 2013 [41] & 2 & 20 & 1 \\
\hline
\end{tabular}

Study of ineffective treatment is labeled gray

$t D C S$ transcranial direct current stimulation

analgesic effects when the session duration was 20-30 min (Table 3).

\section{Session Number}

Session repetition timing may reflect the nonlinear relationship between tDCS settings and the biological effects produced [13, 67]. The tDCS used in the present review achieved an analgesic effect over 5-10 sessions (Table 3).

\section{Potential Analgesic Mechanisms of NIBS}

Unfortunately, the mechanism underlying the analgesic treatment effect of NIBS is unclear. The following three hypotheses have been described in the literature in this review.

\section{Wide Brain Regulation Beyond M1}

Bearing the anatomical evidence of structural and functional connections in mind, the widespread impact of neuromodulation of M1 stimulation to treat NP can be explained $[64,68,69]$. In fact, the effects of rTMS are not only exerted in the area of stimulation, but also spread over the associated cortical, subcortical, and spinal structures. In addition, rTMS on the M1 can modulate the activity of cortical and subcortical regions such as the contralateral M1, thalamus, ACC, somatosensory cortex, insula, and cerebellum. Notably, M1-rTMS consistently interferes with activity in brain areas associated with painful emotions, including the ACC and insula, explaining the effects of M1 stimulation on the emotional aspect of pain $[25,70]$.
Similar to rTMS, the analgesic effects of tDCS may be due to the modulation of the distal neural structures of NP, including sensory-discriminative, cognitive, or emotional aspects of NP [71]. Imaging studies have shown that tDCS additionally affects structures involved in affective, cognitive, and emotional aspects of pain, such as the cingulate and orbitofrontal cortices $[72,73]$.

\section{Activation of the Endogenous Opioid System} However, the mechanisms of NIBS must be multiple and complex, related to the regulation of neural excitability and synaptic plasticity, and involve various neurotransmitter systems, such as endogenous opioids, glutamate, gamma-aminobutyric acid (GABA), and/or dopamine [74, 75]. rTMS of the DLPFC can also cause endogenous opioidergic pain relief when combined with opioid activity [59]. Studies suggest that tDCS in combination with medication-assisted treatment could be an effective strategy in reducing cravings for opioid use $[13,52,76]$.

\section{Promotion of GABA Release}

Cortical inhibition is the neurophysiological process by which GABA-inhibited interneurons selectively attenuate the activity of cortical pyramidal neurons, and impairment of this cortical inhibition is a mechanism associated with NP [63, 77, 78]. HF rTMS produces excitatory effects, and is thought to enhance synapse 
plasticity by inducing long-term potentiation (LTP). In contrast, LF rTMS generates inhibitory effects, presumably through long-term depression (LTD) $[23,79,80]$. rTMS may induce multiple alterations related to LTD and LTP [63]. Magnetic resonance spectroscopy (MRS) studies have shown that atDCS reduces local concentrations of the inhibitory neurotransmitter GABA, whereas ctDCS reduces excitatory glutamate levels [81-83].

\section{DISCUSSION}

NP resulting from lesions or diseases of the nervous system represents an important medical challenge. Our systematic review highlights the analgesic effects of NIBS in patients with NP. It is important to note that NIBS is a noninvasive neuromodulation technique that, although generally well tolerated, warrants special safety considerations for side effects in patient populations, such as local burning, tinnitus, headache, disturbance of grafts, and even induction of seizures. Therefore, the aim of this paper is to summarize the analgesic effects of NIBS on different NPs in order to reduce the occurrence of adverse effects.

In this manuscript, instead of using the classic central and peripheral classifications, we classified the most common (large number of cases) types of NP as typical NP (TNP), including diabetic neuropathy, stroke, spinal cord injury, and nerve injury. The remaining clinically rare types are classified as special NP (SNP), such as facial pain, phantom limb pain, cancer pain, and other types of pain. We hope that this new classification will provide additional benefit in terms of understanding and treating NP. This systematic review reveals that, in general, the optimal therapeutic parameters for rTMS/tDCS and the treatment of NP should allow the design of optimal treatments for individual patients.

Based on the results of the review, the stimulation parameters of rTMS that best induce an analgesic effect are a stimulation frequency of $10-20 \mathrm{~Hz}$, a stimulation intensity of $80-120 \%$ of RMT, 1000-2000 pulses, and 5-10 sessions, and the most effective parameters of tDCS are a current intensity of $2 \mathrm{~mA}$, a session duration of 20-30 min, and 5-10 sessions.

A limitation of this review is that when we summarized the analgesic effect of NIBS, we focused on NP and further divided NP into TNP and SNP. However, we did not involve other types of pain, so it is inevitable that there are some omissions in the summary of the parameters of the analgesic treatment effects of NIBS.

The placebo effect of NIBS can be studied by two means: firstly, the clinicians have positioned an active coil over an area distant from the targeted stimulation area; alternatively, the coil positioned as the targeted stimulation area has been adjusted to an angle of $45^{\circ}$ or $90^{\circ}$ relative to the scalp has from the tangential style [1]. In the present review, 15 reports from a total of 24 rTMS reports as well as four reports from total six tDCS reports have provided the observations and analysis of the placebo effect. In 15 rTMS studies, four have reported that pain scores did not change significantly by sham rTMS, which has indicated the lack of placebo effect of rTMS [24, 26, 28, 37]. In four tDCS studies, two have reported that pain scores did not change significantly by sham treatment, which has indicated the lack of placebo effect of tDCS [16, 40]. Furthermore, all other 11 rTMS reports and two tDCS reports have shown that the pain scores of the subjects could be significantly reduced by active rTMS or tDCS, but not by sham rTMS or sham tDCS.

There are few data related to the long-term benefit of tDCS as a useful tool to alleviate neuropathic pain. Dalla Volta et al. have observed that 3 months after the last tDCS stimulation, the patients with drug-resistant migrainous could still obtain a reduction of $50 \%$ of pain scores [84]. However, some reports have shown that there is no long-term analgesic effect of tDCS on chronic migraine [85] or lung cancer pain [86], while the long-term effect of rTMS on pain relief has been shown in a 6-month study of rTMS treatment in patients with facial pain [42] or with nerve injury induced NP [35]. We have also noticed that the active rTMS could significantly reduce pain intensity with the time course of 25 weeks [79] or even 2.8 years [21]. 
Given that the scientific evidence is still limited, there is a need for multicenter coordination, more randomized controlled studies and the integration of big data to deepen the current understanding of the analgesic mechanisms of rTMS and tDCS.

\section{ACKNOWLEDGEMENTS}

We thank the participants of the study.

Funding. This study and the journal's Rapid Service Fee was supported by the International Science and Technology Cooperation Program of Shaanxi Province to Prof. Hua Yuan (2020KW-050), and the Army innovation Project to Prof. Hua Yuan (16CXZ022). Grants from the Open Project 2018KA01 from State Key Laboratory of Military Stomatology to Prof. YaYun Wang (2018KA01), and the Key R\&D Projects of Shaanxi Province to Prof. Ya-Yun Wang (2018JZ8003).

Authorship. All named authors meet the International Committee of Medical Journal Editors (ICMJE) criteria for authorship for this article, take responsibility for the integrity of the work as a whole, and have given their approval for this version to be published.

Authorship Contributions. Kun-Long Zhang: Conceptualization, Writing- Original draft preparation. Hua Yuan: Conceptualization, Writing- Original draft preparation. Fei-Fei Wu: Conceptualization, Writing- Original draft preparation. Xue-Yin Pu: Investigation, Formal analysis, Visualization. Kai-Feng Li: Investigation, Formal analysis. Bo-Zhi Liu : Investigation, Formal analysis. Ze Li: Investigation, Formal analysis. Yi Yang: Investigation, Formal analysis. Hui Liu: Investigation, Formal analysis. Ya-Yun Wang: Writing - Review \& Editing.

Disclosures. Kun-Long Zhang, Hua Yuan, Fei-Fei Wu, Xue-Yin Pu, Bo-Zhi Liu, Ze Li, KaiFeng Li, Hui Liu, Yi Yang, Ya-Yun Wang have nothing to disclose.
Compliance with Ethics Guidelines. This article is based on previously conducted studies and does not contain any new studies with human participants or animals performed by any of the authors. Written informed consent was obtained for the use of the two patients' photographs in this publication.

Data Availability. The datasets generated during and/or analyzed during the current study are available from the corresponding author on reasonable request.

Open Access. This article is licensed under a Creative Commons Attribution-NonCommercial 4.0 International License, which permits any non-commercial use, sharing, adaptation, distribution and reproduction in any medium or format, as long as you give appropriate credit to the original author(s) and the source, provide a link to the Creative Commons licence, and indicate if changes were made. The images or other third party material in this article are included in the article's Creative Commons licence, unless indicated otherwise in a credit line to the material. If material is not included in the article's Creative Commons licence and your intended use is not permitted by statutory regulation or exceeds the permitted use, you will need to obtain permission directly from the copyright holder. To view a copy of this licence, visit http:// creativecommons.org/licenses/by-nc/4.0/.

\section{REFERENCES}

1. Lefaucheur JP, André-Obadia N, Antal A, et al. Evidence-based guidelines on the therapeutic use of repetitive transcranial magnetic stimulation (rTMS). Clin Neurophysiol. 2014;125(11): 2150-206.

2. Gilron I, Baron R, Jensen T. Neuropathic pain: principles of diagnosis and treatment. Mayo Clin Proc. 2015;90(4):532-45.

3. Hung AL, Lim M, Doshi TL. Targeting cytokines for treatment of neuropathic pain. Scand J Pain. 2017; 17:287-93. 
4. Costa B, Ferreira I, Trevizol A, Thibaut A, Fregni F. Emerging targets and uses of neuromodulation for pain. Expert Rev Neurother. 2019;19(2):109-18.

5. Reincke H, Nelson KR. Duchenne de Boulogne: electrodiagnosis of poliomyelitis. Muscle Nerve. 1990;13(1):56-62.

6. Kolin A, Brill NQ, Broberg PJ. Stimulation of irritable tissues by means of an alternating magnetic field. Proc Soc Exp Biol Med. 1959;102:251-3.

7. Merton PA, Morton HB. Stimulation of the cerebral cortex in the intact human subject. Nature. 1980;285(5762):227.

8. Barker AT, Jalinous R, Freeston IL. Non-invasive magnetic stimulation of human motor cortex. Lancet. 1985;1(8437):1106-7.

9. Andoh J, Matsushita R, Zatorre RJ. Insights into auditory cortex dynamics from non-invasive brain stimulation. Front Neurosci. 2018;12:469.

10. Palm U, Ayache SS, Padberg F, Lefaucheur JP. Noninvasive brain stimulation therapy in multiple sclerosis: a review of tDCS, rTMS and ECT results[J]. Brain Stimul. 2014;7(6):849-54.

11. Cirillo G, di Pino G, Capone F, et al. Neurobiological after-effects of non-invasive brain stimulation. Brain Stimul. 2017;10(1):1-18.

12. Lefaucheur JP, Aleman A, Baeken C, et al. Evidencebased guidelines on the therapeutic use of repetitive transcranial magnetic stimulation (rTMS): an update (2014-2018). Clin Neurophysiol. 2020;131(2):474-528.

13. Lefaucheur JP, Antal A, Ayache SS, et al. Evidencebased guidelines on the therapeutic use of transcranial direct current stimulation (tDCS). Clin Neurophysiol. 2017;128(1):56-92.

14. Malavera A, Silva FA, Fregni F, Carrillo S, Garcia RG. Repetitive transcranial magnetic stimulation for phantom limb pain in land mine victims: a doubleblinded, randomized, sham-controlled trial. J Pain. 2016;17(8):911-8.

15. Misra UK, Kalita J, Bhoi SK. High-rate repetitive transcranial magnetic stimulation in migraine prophylaxis: a randomized, placebo-controlled study. Neurol. 2013;260(11):2793-801.

16. Bolognini N, Olgiati E, Maravita A, Ferraro F, Fregni F. Motor and parietal cortex stimulation for phantom limb pain and sensations. Pain. 2013;154(8): 1274-80.

17. Shamseer L, Moher D, Clarke M, et al. Preferred reporting items for systematic review and meta- analysis protocols (PRISMA-P) 2015: elaboration and explanation. BMJ. 2015;350:g7647.

18. Colloca L, Ludman T, Bouhassira D, et al. Neuropathic pain. Nat Rev Dis Primers. 2017;3:17002.

19. Pommier B, Quesada C, Fauchon C, et al. Added value of multiple versus single sessions of repetitive transcranial magnetic stimulation in predicting motor cortex stimulation efficacy for refractory neuropathic pain. J Neurosurg. 2018. https://doi. org/10.3171/2017.12.JNS171333.

20. Shimizu T, Hosomi K, Maruo T, et al. Efficacy of deep rTMS for neuropathic pain in the lower limb: a randomized, double-blind crossover trial of an H-coil and figure-8 coil. J Neurosurg. 2017;127(5): 1172-80.

21. Pommier B, Créac'h C, Beauvieux V, et al. Robotguided neuronavigated rTMS as an alternative therapy for central (neuropathic) pain: clinical experience and long-term follow-up. Eur J Pain. 2016;20(6):907-16.

22. Hosomi K, Shimokawa T, Ikoma K, et al. Daily repetitive transcranial magnetic stimulation of primary motor cortex for neuropathic pain: a randomized, multicenter, double-blind, crossover, sham-controlled trial. Pain. 2013;154(7):1065-72.

23. Lefaucheur JP, Ayache SS, Sorel M, et al. Analgesic effects of repetitive transcranial magnetic stimulation of the motor cortex in neuropathic pain: influence of theta burst stimulation priming. Eur J Pain. 2012;16(10):1403-13.

24. Lefaucheur JP, Ménard-Lefaucheur I, Goujon C, Keravel Y, Nguyen JP. Predictive value of rTMS in the identification of responders to epidural motor cortex stimulation therapy for pain. J Pain. 2011;12(10):1102-11.

25. Picarelli H, Teixeira MJ, de Andrade DC, et al. Repetitive transcranial magnetic stimulation is efficacious as an add-on to pharmacological therapy in complex regional pain syndrome (CRPS) type I. J Pain. 2010;11(11):1203-10.

26. Ayache SS, Ahdab R, Chalah MA, et al. Analgesic effects of navigated motor cortex rTMS in patients with chronic neuropathic pain. Eur J Pain. 2016;20(9):1413-22.

27. Lefaucheur JP, Jarry G, Drouot X, et al. Motor cortex rTMS reduces acute pain provoked by laser stimulation in patients with chronic neuropathic pain. Clin Neurophysiol. 2010;121(6):895-901.

28. Onesti E, Gabriele M, Cambieri C, et al. H-coil repetitive transcranial magnetic stimulation for 
pain relief in patients with diabetic neuropathy. Eur J Pain. 2013;17(9):1347-56.

29. Sampson SM, Kung S, McAlpine DE, Sandroni P. The use of slow-frequency prefrontal repetitive transcranial magnetic stimulation in refractory neuropathic pain. J ect. 2011;27(1):33-7.

30. De Oliveira RA, De Andrade DC, Mendonça M, et al. Repetitive transcranial magnetic stimulation of the left premotor/dorsolateral prefrontal cortex does not have analgesic effect on central poststroke pain. J Pain. 2014;15(12):1271-81.

31. Kohútová B, Fricová J, Klírová M, Novák T, Rokyta $\mathrm{R}$. Theta burst stimulation in the treatment of chronic orofacial pain: a randomized controlled trial. Physiol Res. 2017;66(6):1041-7.

32. Khedr EM, Kotb HI, Mostafa MG, et al. Repetitive transcranial magnetic stimulation in neuropathic pain secondary to malignancy: a randomized clinical trial[J]. Eur J Pain. 2015;19(4):519-27.

33. Jetté F, Côté I, Meziane HB, Mercier C. Effect of single-session repetitive transcranial magnetic stimulation applied over the hand versus leg motor area on pain after spinal cord injury. Neurorehabil Neural Repair. 2013;27(7):636-43.

34. Lindholm P, Lamusuo S, Taiminen $\mathrm{T}$, et al. Right secondary somatosensory cortex-a promising novel target for the treatment of drug-resistant neuropathic orofacial pain with repetitive transcranial magnetic stimulation. Pain. 2015;156(7):1276-83.

35. Nizard J, Esnault J, Bouche B, et al. Long-term relief of painful bladder syndrome by high-intensity, lowfrequency repetitive transcranial magnetic stimulation of the right and left dorsolateral prefrontal cortices. Front Neurosci. 2018;12:925.

36. Galhardoni R, Aparecida DA, Silva V, García-Larrea $\mathrm{L}$, et al. Insular and anterior cingulate cortex deep stimulation for central neuropathic pain: Disassembling the percept of pain. Neurology. 2019;92(18):e2165-75.

37. Andre-Obadia N, Magnin M, Simon E, Garcia-Larrea L. Somatotopic effects of rTMS in neuropathic pain? A comparison between stimulation over hand and face motor areas. Eur J Pain. 2018;22(4):707-15.

38. Nizard J, Levesque A, Denis $\mathrm{N}$, et al. Interest of repetitive transcranial magnetic stimulation of the motor cortex in the management of refractory cancer pain in palliative care: two case reports. Palliat Med. 2015;29(6):564-8.

39. Attal N, Ayache SS, Ciampi DE, Andrade D, et al. Repetitive transcranial magnetic stimulation and transcranial direct-current stimulation in neuropathic pain due to radiculopathy: a randomized sham-controlled comparative study. Pain. 2016;157(6):1224-31.

40. Soler MD, Kumru H, Pelayo R, et al. Effectiveness of transcranial direct current stimulation and visual illusion on neuropathic pain in spinal cord injury. Brain. 2010;133(9):2565-77.

41. Jensen MP, Sherlin LH, Askew RL, et al. Effects of non-pharmacological pain treatments on brain states. Clin Neurophysiol. 2013;124(10):2016-24.

42. Hodaj H, Alibeu JP, Payen JF, Lefaucheur JP. Treatment of chronic facial pain including cluster headache by repetitive transcranial magnetic stimulation of the motor cortex with maintenance sessions: a naturalistic study. Brain Stimul. 2015;8(4): 801-7.

43. Antal A, Terney D, Kühnl S, Paulus W. Anodal transcranial direct current stimulation of the motor cortex ameliorates chronic pain and reduces short intracortical inhibition. J Pain Symptom Manag. 2010;39(5):890-903.

44. Houde F, Harvey MP, Labrecque PFT, et al. Combining transcranial direct current stimulation and transcutaneous electrical nerve stimulation to relieve persistent pain in a patient suffering from complex regional pain syndrome: a case report. J Pain Res. 2020;13:467-73.

45. di Rollo A, Pallanti S. Phantom limb pain: low frequency repetitive transcranial magnetic stimulation in unaffected hemisphere. Case Rep Med. 2011;2011:130751.

46. Vartiainen N, Perchet C, Magnin M, et al. Thalamic pain: anatomical and physiological indices of prediction. Brain. 2016;139(Pt 3):708-22.

47. Raghu ALB, Parker T, Aziz TZ, et al. Invasive electrical neuromodulation for the treatment of painful diabetic neuropathy: systematic review and metaanalysis. Neuromodulation. 2021;24(1):13-21.

48. Wegener V, Stäbler A, Jansson V, Birkenmaier C, Wegener B. Lumbar burner and stinger syndrome in an elderly athlete. Korean J Pain. 2018;31(1):54-7.

49. Dharmadasa T, Matamala JM, Howells J, et al. The effect of coil type and limb dominance in the assessment of lower-limb motor cortex excitability using TMS. Neurosci Lett. 2019;699:84-90.

50. Luedtke K, Rushton A, Wright C, et al. Effectiveness of transcranial direct current stimulation preceding cognitive behavioural management for chronic low back pain: sham controlled double blinded randomised controlled trial. BMJ. 2015;350:h1640. 
51. Rich TL, Gillick BT. Electrode placement in transcranial direct current stimulation-how reliable is the determination of C3/C4? Brain Sci. 2019;9(3): 69.

52. Mariano TY, Van't Wout M, Garnaat SL, Rasmussen SA, Greenberg BD. Transcranial direct current stimulation (tDCS) targeting left dorsolateral prefrontal cortex modulates task-induced acute pain in healthy volunteers. Pain Med. 2016;17(4):737-45.

53. de Witte S, Klooster D, Dedoncker J, et al. Left prefrontal neuronavigated electrode localization in tDCS: 10-20 EEG system versus MRI-guided neuronavigation. Psychiatry Res Neuroimaging. 2018;274:1-6.

54. Noh TS, Rah YC, Kyong JS, et al. Comparison of treatment outcomes between 10 and 20 EEG electrode location system-guided and neuronavigationguided repetitive transcranial magnetic stimulation in chronic tinnitus patients and target localization in the Asian brain. Acta Otolaryngol. 2017;137(9): 945-51.

55. Lefaucheur JP. Cortical neurostimulation for neuropathic pain: state of the art and perspectives. Pain. 2016;157(Suppl 1):S81-89.

56. Lefaucheur JP. Methods of therapeutic cortical stimulation. Neurophysiol Clin. 2009;39(1):1-14.

57. Quartarone A, Bagnato S, Rizzo V, et al. Distinct changes in cortical and spinal excitability following high-frequency repetitive TMS to the human motor cortex. Exp Brain Res. 2005;161(1):114-24.

58. Maeda F, Keenan JP, Tormos JM, Topka H, PascualLeone A. Interindividual variability of the modulatory effects of repetitive transcranial magnetic stimulation on cortical excitability. Exp Brain Res. 2000;133(4):425-30.

59. Phillips AL, Burr RL, Dunner DL. rTMS effects in patients with co-morbid somatic pain and depressive mood disorders. Affect Disord. 2018;241:411-6.

60. Terranova C, Rizzo V, Cacciola A, et al. Is there a future for non-invasive brain stimulation as a therapeutic tool? Front Neurol. 2018;9:1146.

61. Pitcher D. Facial expression recognition takes longer in the posterior superior temporal sulcus than in the occipital face area. Neurosci. 2014;34(27):9173-7.

62. Novembre G, Ticini LF, Schütz-Bosbach S, Keller PE. Motor simulation and the coordination of self and other in real-time joint action. Soc Cogn Affect Neurosci. 2014;9(8):1062-8.
63. Brighina F, Palermo A, Fierro B. Cortical inhibition and habituation to evoked potentials: relevance for pathophysiology of migraine. Headache Pain. 2009;10(2):77-84.

64. Naro A, Milardi D, Russo M, et al. Non-invasive brain stimulation, a tool to revert maladaptive plasticity in neuropathic pain. Front Hum Neurosci. 2016;10:376.

65. Antal A, Nitsche MA, Kruse W, et al. Direct current stimulation over V5 enhances visuomotor coordination by improving motion perception in humans. J Cogn Neurosci. 2004;16(4):521-7.

66. Shekhawat GS, Sundram F, Bikson M, et al. Intensity, duration, and location of high-definition transcranial direct current stimulation for tinnitus relief. Neurorehabil Neural Repair. 2016;30(4): 349-59.

67. Monte-Silva K, Kuo MF, Hessenthaler S, et al. Induction of late LTP-like plasticity in the human motor cortex by repeated non-invasive brain stimulation. Brain Stimul. 2013;6(3):424-32.

68. Cárdenas-Morales L, Grön G, Kammer T. Exploring the after-effects of theta burst magnetic stimulation on the human motor cortex: a functional imaging study. Hum Brain Mapp. 2011;32(11):1948-60.

69. Ferrarelli F, Haraldsson HM, Barnhart TE, et al. A [17F]-fluoromethane PET/TMS study of effective connectivity. Brain Res Bull. 2004;64(2):103-13.

70. Passard A, Attal N, Benadhira R, et al. Effects of unilateral repetitive transcranial magnetic stimulation of the motor cortex on chronic widespread pain in fibromyalgia. Brain. 2007;130:2661-70.

71. Yoon EJ, Kim YK, Kim HR, et al. Transcranial direct current stimulation to lessen neuropathic pain after spinal cord injury: a mechanistic PET study. Neurorehabil Neural Repair. 2014;28(3):250-9.

72. Maarrawi J, Peyron R, Mertens P, et al. Motor cortex stimulation for pain control induces changes in the endogenous opioid system. Neurology. 2007;69(9): 827-34.

73. Dossantos M, Martikainen I, Nascimento T, et al. Building up analgesia in humans via the endogenous $\mu$-opioid system by combining placebo and active tDCS: a preliminary report. PLOS ONE. 2014;9(7):e102350.

74. Moisset X, de Andrade D, Bouhassira D. From pulses to pain relief: an update on the mechanisms of rTMS-induced analgesic effects. Eur J Pain. 2016;20(5):689-700. 
75. Moisset X, Lefaucheur J. Non pharmacological treatment for neuropathic pain: Invasive and noninvasive cortical stimulation. Revue Neurologique. 2019;175:51-8.

76. Young JR, Smani SA, Mischel NA, et al. Non-invasive brain stimulation modalities for the treatment and prevention of opioid use disorder: a systematic review of the literature. J Addict Dis. 2020;38(2): 186-99.

77. Barr MS, Farzan F, Davis KD, Fitzgerald PB, Daskalakis ZJ. Measuring GABAergic inhibitory activity with TMS-EEG and its potential clinical application for chronic pain. Neuroimmune Pharmacol. 2013;8(3):535-46.

78. Curra A, Pierelli F, Coppola G, et al. Shortened cortical silent period in facial muscles of patients with migraine. Pain. 2007;132(1-2):124-31.

79. Mhalla A, Baudic S, Ciampi DE, Andrade D, et al. Long-term maintenance of the analgesic effects of transcranial magnetic stimulation in fibromyalgia. Pain. 2011;152(7):1478-85.

80. Dossantos M, Oliveira A, Ferreira N, Carvalho A, Rosado DC. The contribution of endogenous modulatory systems to TMS- and tDCS-induced analgesia: evidence from PET studies. Pain Res. 2018;2018: 2368386.

81. Clark V, Coffman B, Trumbo M, Gasparovic C. Transcranial direct current stimulation (tDCS) produces localized and specific alterations in neurochemistry: a ${ }^{1} \mathrm{H}$ magnetic resonance spectroscopy study. Neurosci Lett. 2011;500(1):67-71.

82. Krause B, Márquez-Ruiz J, Cohen KR. The effect of transcranial direct current stimulation: a role for cortical excitation/inhibition balance? Front Hum Neurosci. 2013;7:602.

83. Misra U, Kalita J, Bhoi S. High-rate repetitive transcranial magnetic stimulation in migraine prophylaxis: a randomized, placebo-controlled study. J Neurol. 2013;260(11):2793-801.

84. Dalla VG, Carli D, Zavarise P, Antonaci F. 0033. TDCs treatment: long term results in drug resistant migrainous patients. J Headache Pain. 2015;16(Suppl 1):A178.

85. Grazzi L, Usai S, Bolognini N, et al. No efficacy of transcranial direct current stimulation on chronic migraine with medication overuse: a double blind, randomised clinical trial. Cephalalgia. 2020;40(11): 1202-11.

86. Stamenkovic DM, Mladenovic K, Rancic N, et al. Effect of transcranial direct current stimulation combined with patient-controlled intravenous morphine analgesia on analgesic use and post-thoracotomy pain. A prospective, randomized, doubleblind, sham-controlled, proof-of-concept clinical trial. Front Pharmacol. 2020;11:125. 